\title{
People and work: some contemporary issues
}

\author{
SYLVIA SHIMMIN \\ Department of Behaviour in Organisations, University of Lancaster, Furness College, \\ Bailrigg, Lancaster, LA1 4YG.
}

\begin{abstract}
Shimmin, Sylvia (1975). British Journal of Industrial Medicine, 32, 93-101. People and work: some contemporary issues. In advanced industrial societies social, economic, and technological changes are accompanied by changing values and attitudes to work, symptomatic of what some see as the transition to a post-industrial era. As a result existing job definitions and traditional forms of organization are being challenged and attempts made to restructure work so that it becomes meaningful and rewarding in the fullest sense, to the individual, to the enterprise, and to society. These range from programmes of job enlargement and job enrichment, within the framework of existing technologies, to experiments in the design of organizations as a whole in which fewer constraints are accepted as given. They entail and require a multidisciplinary approach as well as awareness of and commitment to the underlying values. The possibilities and benefits of restructuring work in these various ways have been demonstrated sufficiently to encourage interest at governmental level as well as by employers and trade unions. There are, however, no simple prescriptions or principles of universal application. Knowledge is still tentative and partial but there is consensus that the search for new ways of dealing with the organization of work and the allocation of resources is of fundamental importance.
\end{abstract}

Two years ago the Department of Employment published a report (Wilson, 1973) which in its origin, title, and contents illustrates the theme and context of much contemporary occupational psychology. It was commissioned by the Department as the consequence of a request from the NATO Committee on the Challenges of Modern Society for an enquiry into problems of work motivation and satisfaction, indicating the interest in this topic which exists at both a national and international level. The author, although a psychologist, necessarily drew upon sources from other disciplines as well as his own because the study of behaviour and attitudes of people at work cannot be confined within any one set of academic boundaries. Entitled 'On the Quality of Working Life' it employs a phrase which is gaining in popularity but which presents social scientists with value issues in relation to their professional activities in studying work, in that quality unlike quantity is an evaluative judgement and cannot be assessed by objective measures. These three aspects - the stimulus from governmental and international bodies in promoting discussions between themselves, employers, trade unions, and research workers; the multidisciplinary approach required to study work in a changing industrial society; and the recognition that, in such an applied field, social scientists cannot be 'value-free'-seem likely to influence research and practice throughout this decade. Reasons for this development and some of the major influences shaping current thinking on the subject are discussed in this article.

\section{Social change}

The growth of the factory system and the design and organization of work in terms of rationalization, specialization, and subdivision of tasks, epitomized in assembly-line production, was associated with a social ethic attaching value to hard work and to the 
whole concept of 'earning a living'. This has prevailed over a long period in which advances in technology have enhanced the possibilities of specialization and external control in work of all kinds. The guiding principle of most of our social institutions, as an Organisation for Economic Cooperative and Development (1973) report points out, has been and still is that of preparing people for and maintaining them in jobs arising directly and indirectly from industrialization and technological innovation.

There are signs now that the situation is changing. These were described by Cherns (1973a) in his presidential address to Section $\mathbf{N}$ of the British Association and are indicative of what Bell (1967), Davis (1971), and others contend is a transition from an industrial to a post-industrial era. They include the decline in manufacturing industry as the principal type of employment, the refusal of young people in the developed countries to undertake jobs which deny them personal satisfaction, to opt out of 'work' altogether or to engage in jobs which are only on the fringe of so-called normal activity, and the choice by older people to spend a smaller proportion of their lives at work by means of longer holidays, a shorter working week, and earlier retirement. None of these trends is on a sufficiently large scale as yet for general public awareness of the nature and extent of the transition, although they are the subject of social comment. In industrialized Europe some aspects of the situation are obscured by the widespread employment of workers from less developed countries in jobs which increasing numbers of the indigenous population are not prepared to do.

Accompanying these patterns in social behaviour are the emergence of new values and changes in the relative importance of others which Trist (1970) has categorized under three headings. Examples of the first, cultural values, are the emphasis on selfdiscovery and self-expression rather than on achievement and self-control; of the second, organizational philosophies, on participation and involvement in decisions rather than on conformity to a hierarchy of authority; and of the third, ecological strategies, on long-term planning horizons rather than short-term, on enlarged rather than small local government units, and on co-ordinated rather than separate services. While not disputing the existence of these changes in our organized society, Child (1974) sees the emphasis on growth in size as evidence of 'doublethink', i.e., the holding of contradictory values simultaneously. In his view, large-scale organization tends towards bureaucracy and specialization of function which is at variance with the increasing value attached to self-determination and democratic decision-making.

To some extent these apparently incompatible tendencies may be symptomatic of the problem of changing outlooks and social institutions to those appropriate to a post-industrial era. These invariably lag behind technical and economic possibilities and, as Cherns (1973a) argues, when the change required of society is as radical as its definition of work on which its institutions rest, an intense and prolonged crisis is inevitable. This is the background to present discontents, so frequently ascribed solely to inflation. It also accounts for the intense interest being shown in official circles in all advanced societies in examining the nature of work, its significance for the individual and society, and in ways of designing jobs which will meet the needs and expectations of both.

\section{Man and work: some frames of reference}

Classical industrial psychology sought to explain and predict behaviour at work in terms of causal models, an approach which Hinrichs (1970) claims is now almost universally recognized as inadequate. He maintains that a systems framework is essential to describe the dynamics of the interactions involved as it permits consideration of organizational variables other than those specifically related to an individual's job.

Daniel (1973) distinguishes between two major approaches, one adopted by certain American social psychologists and the other associated particularly with some British sociologists. The former, as exemplified by writers like McGregor (1960), are 'psychologically universalistic' in suggesting that certain needs are shared by workers of all types and levels and that their response to the work situation can be explained in terms of the extent to which these needs are satisfied. In the latter approach, of which Goldthorpe and his colleagues (1968) are the main exponents, it is maintained that the expectations which the worker brings to his job as a result of his social experiences and relationships outside work are the key to understanding industrial behaviour.

Most sociopsychological approaches have tended to focus very much on the context of work and upon attitudes and satisfaction in the workplace. According to Davis (1971), a major criticism of studies by Katzell, Barrett, and Parker (1961), Dunnette, Campbell, and Hakel (1967), Blood and Hulin (1967), and Hulin (1969), which seek to correlate economic, community, group, and personality variables with workers' attitudes and job satisfaction, is their failure to study the work itself. By this he does not mean totally ignoring the content of jobs but the taking of technology as a given, as a result of which occupational adjustment is considered within the context of existing systems of work rather than exploring how satisfaction might beincreased through job design. For occupational psychologists who deal 
with problems of fitting the man to the job and the job to the man this insistence on studying the task itself is not new, as Rodger and Guest (1969) point out, although its central importance has not been fully appreciated until recently.

The possibilities of choice in work organization within the limits set by technology have been demonstrated in the studies by members of the Tavistock Institute of Human Relations such as Rice (1958), Trist et al. (1963), and Miller and Rice (1967). This approach is based on the concept of a sociotechnical system which regards the enterprise-as-a-whole as a system of social action, comprising distinct yet interrelated technological, sociopsychological, and economic components. Associated with, and deriving from this work are the Norwegian experiments in industrial democracy reported by Emery and Thorsrud (1969) and Thorsrud (1970), which bring the question of transferring to work groups some of management's traditional authority for the control and co-ordination of work into the current debate on job design and job satisfaction. In so doing, the tendency to neglect differences in the power of management and labour and their potential conflicts of interest, with which Daniel (1973) charges many social scientists, is met to some extent although the implications for institutional industrial relations have still to be explored in full.

\section{Job satisfaction, job enlargement, and job enrichment}

As Chichester-Clark (1973) has stated, any consideration of the quality of working life includes the area covered by such terms as job satisfaction, job enrichment, and job enlargement. These are not easily differentiated by the layman and are not always used in precisely the same way by professionals.

The concept of job satisfaction, that is of the satisfaction experienced by individuals with their jobs in terms not only of the task performed but also of the total work situation, including factors such as pay, conditions, and relations with managers and fellow workers, has a long history. Early studies, such as the classic one by Hoppock (1935), were concerned with the relationship between attitudinal measures and particular aspects of the work situation, for example the degree of acceptance by fellowworkers (van Zelst, 1951; Zaleznik, Christensen, and Roethlisberger, 1958) rather than with intrinsic job content. This was not overlooked so much as studied by different people in a somewhat different context, as for instance in the investigations of fatigue and boredom induced by repetitive work carried out in this country under the auspices of the Industrial Fatigue Research Board (Vernon, Wyatt, and Ogden, 1924; Wyatt, Fraser, and Stock, 1929) and subse- quently the Industrial Health Research Board (Wyatt, Langdon, and Stock, 1937). Here the initial emphasis was on the incidence of boredom in different types of work and how it might be alleviated, including experiments with systematic variations in work activity. This anticipated by some years the use and development of the idea of job enlargement, associated with studies made at the Institute for Social Research, University of Michigan in the 1950s and particularly influenced by those of Walker (1950) on repetitive jobs and assembly line work (Walker and Guest, 1952).

Job enlargement is generally taken to mean providing greater variety within the compass of an individual's job without requiring the exercise of any greater level of skill or responsibility, as distinct from job enrichment (or vertical job enlargement) in which the addition of tasks or extension of the work requires greater responsibility and self-regulation by those performing the job. Both terms have been associated with Herzberg $(1966 ; 1968)$ and with a fierce controversy among psychologists in the United States over his two-factor theory of job satisfaction.

An empirical study of the job attitudes of engineers and accountants (Herzberg, Mausner, and Snyderman, 1959) first led Herzberg to distinguish between intrinsic or 'motivating' factors and extrinsic or 'hygiene' factors in the work situation and to suggest that the two sets of factors contribute differentially to the separate conditions of job satisfaction and job dissatisfaction. According to King (1970), much of the controversy over the two-factor theory can be attributed to lack of clear exposition by the researchers concerned, and he identifies five different versions, stated or implied, in publications by Herzberg (1966), Dunnette et al. (1967), House and Wigdor (1967), Lindsay, Marks, and Gorlow (1967), and Whitsett and Winslow (1967). These variations do not detract from the basic contention that there is a fundamental difference between what leads to positive satisfaction, namely the achievement, recognition, and self-fulfilment stemming from the job itself, and the conditions of work such as pay, supervisory style, and physical environment which, if not adequate, lead to dissatisfaction. For many managers this has face validity because it explains why measures taken to remove grievances and improve conditions fail to evoke a positive response from their workpeople. It has therefore focused their attention on job content and led to deliberate attempts to improve motivation to work through job enrichment programmes (Paul, Robertson, and Herzberg, 1969; Paul and Robertson, 1970; Cotgrove, Dunham, and Vamplew, 1971).

Some of the arguments about job enlargement and job enrichment are spurious in the opinion of Davis (1971) because of the tendency of some researchers to treat the terms as synonymous, leading to mis- 
interpretation by protagonists such as Kilbridge (1960) and MacKinney, Wernimont, and Galitz (1962) of the views of Argyris (1957; 1964), Davis (1957a; 1957b), Guest (1957), and Davis and Werling (1960). However, confusion of terminology continues, as may be observed in a recent article by Susman (1973) in which enlarged jobs are defined as those which allow workers more discretion and responsibility through redesigned technology, workflow or increased delegation to the job holder. Hulin and Blood (1968) give a similar definition.

Use of the term enlargement to cover both the vertical and horizontal dimension of enhancing job content would not matter were it not that these dimensions often represent different philosophies of man and his work. Vertical enlargement or enrichment challenges prevailing concepts about the organization of work and the motivation of workers and seeks to change them. Horizontal enlargement, on the other hand, aims at more varied job content within the framework of the existing situation and does not entail any fundamental change in the status or responsibility of the individual worker. In this context, as Chichester-Clark (1973) suggests, job rotation whereby individuals move between jobs, usually at regular intervals but sometimes on a more informal basis within a work group, may be regarded as a special form of job enlargement.

\section{Research and application}

Experiments and investigations designed to test assertions about the organization of work and its consequences face the problem that these assertions usually embody both empirically testable statements of the effects of certain conditions, and non-empirical values that some outcomes or psychological states are intrinsically superior to others. For example, Cherns (1973b) points out that the 'open sociotechnical system' approach of the Tavistock Institute and its associates is frankly ideological; its two value judgements are that autonomy and interdependence are not only adaptive values in most work situations but are social goods in their own right, and that selfinvolvement in work is a positive human value. Likewise, Fox (1971) notes how the self-actualization school, represented by Maslow (1954) and his followers, shares with Marx (Bottomore and Rubel, 1963) a moral ideal of man, variously described as healthy, normal, mature or self-actualizing, which can be realized or denied by the normative system which structures the work situation. On such issues it is inevitable that research workers adopt a valueladen approach in their enquiries as was noted by Warr (1973), Cherns (1973b), Jackson (1973), and Pym (1973) in a symposium on better working lives.

Studies of job satisfaction are seen by Vroom (1964) as of two main kinds: those seeking to identify the determinants of job satisfaction and those concerned with the relation between job satisfaction and work performance. Although lack of standardized measures makes comparison between studies. difficult, a criticism made also by Brayfield and Crockett (1955) and Fournet, Distefano, and Pryer (1966) among others, he concludes that job satisfaction must be assumed to be the result of the operation of both situational and personality variables; and that the absence of a marked or consistent correlation between job satisfaction and performance makes it desirable to treat them as separate outcomes of the person-work role relationship. Handyside and Speak (1964), using a questionnaire technique, found clear evidence of the multidimensional nature of job satisfaction and maintain that it is scientifically unjustifiable to try to relate a global measure of generalized job satisfaction to worker efficiency. Similarly, Susman (1973) advises caution in interpreting workers' responses to increased discretion in their jobs when assessed against an omnibus measure of job satisfaction as, for example, in the studies by Turner and Lawrence (1965).

The Herzberg two-factor theory developed from research using a critical incidents approach (Herzberg et al., 1957; 1959). In essence, this asks the respondent to relate incidents connected with a time when he felt either exceptionally good or bad about his job. Ewen (1964) argues that this method, when used alone, is subject to the bias of selective recall of certain incidents to the exclusion of others. Vroom and Maier (1961) also point to the risk of an individual attributing satisfactions to aspects of the job which reflect or enhance his self-esteem and of assigning dissatisfactions to environmental factors rather than to any personal inadequacies. In other words, the dichotomous nature of job satisfaction propounded by Herzberg and his associates may be an artifact of their method of study.

Despite the methodological limitations which make it difficult to refute or confirm claims of universal applicability, experiments in the design of jobs and restructuring of work are extending. Some of the most publicized are those in the Swedish car industry although, as Edgren (1974) has shown, similar experiments are also being made with other types. of production systems in Sweden. Work organization. experiments of this kind are not only in the job enrichment tradition but are based on other approaches, often of a multidisciplinary kind, the origins of which are described by Foster (1968) and Klein (1974). They are characterized by action research, entailing the research workers' active involvement in planning and implementing change, modifying procedures in response to feedback, and sharing responsibility for the outcome with members of the organization concerned. As Shimmin (1971), Cherns (1973a), and others have pointed out, this. 
practitioner-client relationship leads to a very different role for the research worker from the traditional one of an independent, detached observer; the procedures followed are not subject to the same checks as other scientific methods nor are the results obtained subject to the same process of validation.

\section{Criteria for job design}

Job design is defined by Davis (1966) as the specification of the contents, methods, and relationships of jobs in order to satisfy technological and organizational requirements as well as the social and personal requirements of the job-holder. An outline of the history of developments in job design has been given by Smyth (1967) in which he points out that the detrimental effects of imposed pacing of work, specialization, and subdivision of tasks, characteristic of the industrial era, have been demonstrated experimentally. Although social scientists are by no means unanimous about the nature, causes, and consequences of job satisfaction, and knowledge of the desirable components of jobs is still tentative, the following principles put forward by Emery and Thorsrud (1969) are recognized as guide-lines for job design:

1. At the level of the individual:

(a) Optimum variety of tasks within the job Too much variety can be inefficient for training and production as well as frustrating for the worker. However, too little can be conducive to boredom or fatigue. The optimum level would be that which allows the operator to take a rest from a high level of attention or effort in a demanding activity while working at another, and conversely allows him to stretch himself and his capacities after a period of routine activity.

(b) A meaningful pattern of tasks that gives to each job a semblance of a single overall task The tasks should be such that although involving different levels of attention, degrees of effort, or kinds of skill, they are interdependent: that is, the carrying out of one task makes it easier to get on with the next or gives a better end result to the overall task. Given such a pattern, the worker can help to find a method of working suitable to his requirements, and he can more easily relate his job to that of others.

(c) Optimum length of work cycle Too short a cycle means too much finishing and starting; too long a cycle makes it difficult to build up a rhythm of work.

(d) Some scope for setting standards of quantity and quality of production and a suitable feedback of knowledge of results Minimum standards generally have to be set by management to determine whether :a worker is sufficiently trained, skilled or careful to hold the job. Workers are more likely to accept responsibility for higher standards if they have some freedom in setting them and are more likely to learn from the job if there is feedback. They can neither effectively set standards nor learn if there is not a quick enough feedback of knowledge of results.

(e) Inclusion in the job of some of the auxiliary and preparatory tasks The worker cannot and will not accept responsibility for matters outside his control. In so far as the preceding criteria are met, then the inclusion of such 'boundary tasks' will extend the scope of the worker's responsibility and make for involvement in the job.

(f) The tasks included in the job should include some degree of care, skill, knowledge or effort that is worthy of respect in the community.

(g) The job should make some perceptible contribution to the utility of the product for the consumer.

\section{At the level of the group:}

(h) Providing for 'interlocking' tasks, job rotation or physical proximity where there is a necessary interdependence of jobs (for technical or psychological reasons). At a minimum this helps to sustain communication and to create mutual understanding between workers whose tasks are interdependent and thus lessens friction, recriminations, and 'scapegoating'. At best this procedure will help to create work groups that enforce standards of co-operation and mutual help.

(i) Providing for interlocking tasks, job rotation or physical proximity where the individual jobs entail a relatively high degree of stress Stress can arise from apparently simple things, such as physical activity, concentration, noise or isolation, if these persist for long periods. Left to their own devices people will become habituated, but the effects of the stress will tend to be reflected in more mistakes, accidents, and the like. Communication with others in a similar plight tends to lessen the strain.

(j) Providing for interlocking tasks, job rotation or physical proximity where the individual jobs do not make an obvious perceptible contribution to the utility of the end product.

(k) Where a number of jobs are linked together by interlocking tasks or job rotation they should as a group:

(i) have some semblance of an overall task which makes a contribution to the utility of the product;

(ii) have some scope for setting standards and receiving knowledge of results; 
(iii) have some control over the 'boundary tasks' (i.e., tasks of service or voluntary character).

(l) Provision of channels of communication so that the minimum requirements of the workers can be fed into the design of new jobs at an early stage;

(m) Provision of channels of promotion to foreman rank which are sanctioned by the workers.

These criteria were not meant to be final, and Thorsrud (1972) stresses that there is no simple technique which can be applied in all industrial conditions to bring about these changes. Thus job enrichment and job enlargement may be effective in some conditions but inappropriate in others; autonomous work groups are appropriate to some production systems but not others; and, although few technologies are so intractable as to be susceptible of no improvement, existing technology may limit the extent to which the desired changes may be made in the content of certain jobs.

\section{Organization design and development}

The systemic nature of organizations means that changes in one part of the system leads to changes in other parts, so it is not surprising that from the theory and practice of job design has now emerged the idea of organizational design. In this the behavioural scientist is an integral member of a multidisciplinary design team seeking to achieve joint optimization of the social and technical systems which comprise the enterprise. Clark (1972) describes it as a new and emergent activity concerned with the designing of systems of organization including co-ordination, control, and decision-making. He claims that it is the only approach which deals with the aspects of the work situation identified by Herzberg as being critical to the performance and motivation of the employee, i.e., the opportunities provided by the job itself for control, autonomy, and advancement. This is in contrast with approaches to organizational change in which work design is seen as a function of industrial engineering and behavioural science as a means of assisting individuals and groups to cope with and adapt to changing technology. These are often described as 'planned organizational change' or organization development, although here again it must be noted that different practitioners may use the terms somewhat differently from one another.

Organization development is defined by Beckhard (1969) as planned organization-wide effort, managed from the top, to increase organizational effectiveness and health through planned interventions in organizational processes, using behavioural science knowledge. Bennis (1969) states that it is a complex educational strategy intended to change the beliefs, attitudes, values, and structure of organizations so that they can better adapt to new technologies, markets, challenges, and the rate of change itself. Although Beckhard cites a case of redistribution of tasks as one of many strategies of organization development, Bennis admits that far more emphasis is put on effective interpersonal relationships than on structural factors. He maintains that organization development practitioners or 'change-agents' tend to see their work as introducing meaningful interpersonal relationships into the working environment and rely on a change in organizational 'climate' to produce the desired problem-solving, adaptive outlook within the enterprise. Hence organization development has been mistakenly thought by some to be solely or largely a matter of sensitivity training.

Central to both organizational design and development are questions on the order and precedence of subsystem change. As Taylor (1971) observes, we still do not know whether technical change is the best way of achieving organizational change or whether it would be better to make a purposeful change in the social system, following this by planned changes in organizational technology, or to change both simultaneously. In his opinion, although there is evidence for asserting that planning for social change should whenever possible take place around technological change, the evidence is not unambiguous. Nor is it clear whether one sort of change strategy will work better with some people than others, or will have more permanent effects.

At present, therefore, knowledge about organizational design is tentative. Recognition of the possibilities of organizational choice is extending but the problem of accommodating individual preferences and differences within organized frameworks subject to varying operational and environmental constraints is highly complex. The search for universal prescriptions dies hard, although the contingency theory approach, summarized by Lupton (1971) and Child (1972), which specifies that organizations should be designed to meet their particular circumstances, marks an advance on earlier approaches seeking generally applicable principles and techniques for allocating and controlling work. Child (1973), however, regards contingency theory as unduly conservative in many ways because it takes certain constraints for granted and ignores the political and ideological aspects inherent in organizational design and decision-making. He contends that there is probably far more choice in the design of organization than is generally suggested by the literature and that in future there will be mounting pressure for decisions of this kind to be made with reference to a much broader framework of costs and benefits than prevails today.

\section{Future trends}

It is difficult to evaluate the current status of these 
different attempts to improve the quality of working life and to predict future developments for a number of reasons, first, because as Thorsrud (1972) and others have stressed, experimental programmes need protection from outside interference and undue publicity if they are to become natural rather than exceptional events. For this reason some organizations which are undertaking significant studies do not wish it to be known lest these are distorted by getting into the limelight. Indeed some people contend that the most important developments are being kept secret for this reason, a view which it is impossible to refute or confirm. Second is the problem mentioned by Wilson (1973) that recorded successes are usually on a small scale, do not seem to diffuse widely, and often are not expected to continue at peak level for more than a few years at most. How to generate self-sustaining programmes is still not fully understood. Third is the provisional state of knowledge, accentuated by the authoritative but contrary opinions expressed by some of the major contributors to the field. As Wilson puts it, we need more knowledge, more experience, and more systematic and controlled trials.

There seems no doubt however that work design and restructuring, whether at the level of individual, group or organizational activities, is not a passing fashion. It may be seen as an attempt to meet the needs of a competitive economy in a changing social and political environment, characterized by changing values and attitudes to work as it affects the whole of life. The establishment of a tripartite steering group on job satisfaction by the British Secretary of State for Employment in July 1973,which was re-convened by the Labour government when it first took office in 1974, illustrates the seriousness with which the issue is regarded in official circles. Arising from the deliberations of this steering group a research programme has been initiated, and within the Department of Employment a research unit on work has been set up to provide advice, information, consultancy, and research.

Experimental programmes may be anticipated in all spheres of work and not merely in manufacturing industry. Because most of the well-documented cases to date have come from the latter, there is a tendency for some to see attempts to improve work systems as restricted to this area. However, the development of open-plan offices, accompanied by increased mechanization, electronic data processing, and a stress on productivity akin to that found in manufacturing industry, has made the work of many clerical workers more like that of the shopfloor. Similarly, growth in the size of organizations and of the scale of their operations has increased the number of routinized administrative jobs in both the public and private sector. These examples illustrate that alienation, another widely used term with a variety of meanings, in the sense of the individual failing to relate meaningfully to his work (Emery, 1972), is not confined to any one group of occupations.

For occupational psychology the implications are that the subject is likely to show an increasingly organizational emphasis and orientation, already evident in much teaching and research. As Schein (1970) puts it, the relationship between the individual and the organization is interactive, so that the psychological dynamics of behaviour cannot be understood if we look only to the individual's motivations or only to organizational conditions and practices. In seeking to discover what forms of organization are appropriate to particular circumstances, the psychologist has a distinctive contribution to make alongside other specialists in furthering knowledge of the nature of this interaction, the complexity of which is beyond the confines of a single discipline.

\section{References}

Argyris, C. (1957). Personality and Organization. Harper and Row, New York.

(1964). Integrating the Individual and the Organization. Wiley, New York.

Beckhard, R. (1969). Organization Development: Strategies and Models. Addison-Wesley, Reading, Mass.

Bell, D. (1967). Notes on the post-industrial society: I and II. Public Interest, 6 and 7.

Bennis, W. G. (1969). Organization Development: Its Nature, Origins and Prospects. Addison-Wesley, Reading, Mass.

Blood, M. R. and Hulin, C. L. (1967). Alienation, environmental characteristics and worker responses. Journal of Applied Psychology, 51, 284-290.

Bottomore, T. B. and Rubel, M. eds. (1963). Karl Marx: Selected Writings in Sociology and Social Philosophy. Penguin, Harmondsworth.

Brayfield, A. H. and Crockett, W. H. (1955). Employee attitudes and employee performance. Psychological Bulletin, 52, 396-424.

Cherns, A. B. (1973a). Work or Life. Section N. Presidential Address, British Association for the Advancement of Science (mimeograph).

(1973b). Better working lives-a social scientist's view. Occupational Psychology, 47, 23-28.

Chichester-Clark, R. (1973). On the quality of working life. Personnel Management, 5, no. 11, 26-29.

Child, J. (1972). Organizational structure, environment and performance-the role of strategic choice. Sociology, 6, 1-22.

(1973). Organization: a choice for man. In Man and Organization, edited by J. Child. Allen and Unwin, London.

(1974). Doublethink in our organized society. Inaugural lecture, The University of Aston in Birmingham.

Clark, P. A. (1972). Organizational Design: Theory and Practice. Tavistock, London.

Cotgrove, S., Dunham, J., and Vamplew, C. (1971). The 
Nylon Spinners. Allen and Unwin, London.

Daniel, W. W. (1973). Understanding employee behaviour in its context: illustrations from productivity bargaining. In Man and Organization, edited by J. Child. Allen and Unwin, London.

Davis, L. E. (1957a). Toward a theory of job design. Journal of Industrial Engineering, 2, 305-309.

(1957b). Job design and productivity: a new approach. Personnel, 33, 418-430.

- (1966). The design of jobs. Industrial Relations, 6, 21-45.

- (1971). Job satisfaction research: the post-industrial view. Industrial Relations, 10, 176-193.

—_ and Werling, R. (1960). Job design factors. Occupational Psychology, 34, 108-132.

Dunnette, M. D., Campbell, J. P., and Hakel, M. (1967). Factors contributing to job satisfaction and job dissatisfaction in six occupational groups. Organizational Behaviour and Human Performance, 2, 143-174.

Edgren, J. (1974). Swedish experiments in work organization. Personnel Management, 6, no. 6, 25-27, 40.

Emery, F. E. (1972). Characteristics of socio-technical systems. In Design of Jobs, edited by L. E. Davis and J. C. Taylor. Penguin, Harmondsworth.

- and Thorsrud, E. (1969). Form and Content in Industrial Democracy. Tavistock, London.

Ewen, R. B. (1964). Some determinants of job satisfaction: a study of the generality of Herzberg's theory. Journal of Applied Psychology, 48, 161-163.

Foster, M. (1968). Work involvement and alienation. Manpower and Applied Psychology, 2, 35-48.

Fournet, G. P., Distefano, M. K., and Pryer, M. W. (1966). Job satisfaction: issues and problems. Personnel Psychology, 19, 165-183.

Fox, A. (1971). A Sociology of Work in Industry. CollierMacMillan, London.

Goldthorpe, J. H., Lockwood, D., Bechhofer, F., and Platt, J. (1968). The Affluent Worker: Industrial Attitudes and Behaviour. Cambridge University Press, London.

Guest, R. H. (1957). Job enlargement-a revolution in job design. Personnel Administration, 20, 9-16.

Handyside, J. D. and Speak, B. M. (1964). Job satisfaction: myths and realities. British Journal of Industrial Relations, 2, 57-65.

Herzberg, F. (1966). Work and the Nature of Man. World Publishing, New York.

(1968). One more time: how do you motivate employees? Harvard Business Review, 46, 53-62.

—, Mausner, B., Peterson, R. O., and Capwell, D. F. (1957). Job Attitudes: Review of Research and Opinion. Psychological Service of Pittsburgh, Pittsburgh.

,-- , and Snyderman, B. (1959). The Motivation to Work. Wiley, New York.

Hinrichs, J. R. (1970). Psychology of men at work. Annual Review of Psychology, 21, 519-554.

Hoppock, R. (1935). Job Satisfaction. Harper and Row, New York.

House, R. J. and Wigdor, L. A. (1967). Herzberg's dualfactor theory of job satisfaction and motivation: a review of the evidence and a criticism. Personnel Psychology, 20, 369-389.
Hulin, C. L. (1969). Sources of variation in job and life satisfaction: the role of community and job-related variables. Journal of Applied Psychology, 53, 279-291. and Blood, M. R. (1968). Job enlargement, individual differences and worker responses. Psychological Bulletin, 69, 41-55.

Jackson, P. (1973). Better working lives-an organisational consultant's view. Occupational Psychology, 47, 29-31.

Katzell, R. A., Barrett, R. S., and Parker, T. C. (1961). Job satisfaction, job performance and situational characteristics. Journal of Applied Psychology, 45, 65-72.

Kilbridge, M. D. (1960). Do workers prefer larger jobs? Personnel, 37, 45-48.

King, N. (1970). Clarification and evaluation of the twofactor theory of job satisfaction. Psychological Bulletin, 74, 18-31.

Klein, L. (1974). New Forms of Work Organisation. Report to the Kommission für wirtschaftlichen und sozialen Wandel (mimeograph).

Lindsay, C. A., Marks, E., and Gorlow, L. (1967). The Herzberg theory: a critique and reformulation. Journal of Applied Psychology, 51, 330-339.

Lupton, T. (1971). Management and the Social Sciences, 2nd edition. Penguin, Harmondsworth.

McGregor, D. (1960). The Human Side of Enterprise. McGraw-Hill, New York.

MacKinney, A. C., Wernimont, P. F., and Galitz, W. O. (1962). Has specialisation reduced job satisfaction? Personnel, 39, 8-17.

Maslow, A. H. (1954). Motivation and Personality. Harper, New York.

Miller, E. J. and Rice, A. K. (1967). Systems of Organization: The Control of Task and Sentient Boundaries. Tavistock, London.

Organisation for Economic Cooperation and Development (1973). New Patterns for Working Time. Final Report of International Conference, Paris, September 1972. Paris: Organisation for Economic Co-operation and Development.

Paul, W. J. and Robertson, K. B. (1970). Job Enrichment and Employee Motivation. Gower Press, London.

_ _ _ and Herzberg, F. (1969). Job enrichment pays off. Harvard Business Review, 47, 61-78.

Pym, D. (1973). Better working lives? A personal view point. Occupational Psychology, 47, 33-36.

Rice, A. K. (1958). Productivity and Social Organization. The Ahmedabad Experiment. Tavistock, London.

Rodger, A. and Guest, D. (1969). Occupational psychology. In Psychology in Great Britain: Supplement to the Bulletin of the British Psychological Society, edited by B. M. Foss. XIX International Congress of Psychology. Tavistock Publications, London.

Schein, E. (1970). Organizational Psychology, 2nd edition. Prentice-Hall, Englewood Cliffs, New Jersey.

Shimmin, S. (1971). Behaviour in organisations: problems and perspectives. Occupational Psychology, 45, 13-26.

Smyth, L. F. (1967). Job design in a socio-technical system. Manpower and Applied Psychology, 1, 130-134. Susman, G. I. (1973). Job enlargement: effects of culture 
on worker responses. Industrial Relations, 12, 1-15.

Taylor, J. C. (1971). Some effects of technology in organizational change. Human Relations, 24, 105-123.

Thorsrud, E. (1970). A strategy for research and social change in industry: a report on the industrial democracy project in Norway. Social Science Information, 9, no. 5, 65-90.

(1972). Job design in the wider context. In Design of Jobs, edited by L. E. Davis and J. C. Taylor. Penguin, Harmondsworth.

Trist, E. L. (1970). Urban North America: the challenge of the next thirty years. Journal of the Town Planning Institute of Canada, 10, 4-20.

—, Higgin, G. W., Murray, H., and Pollock, A. B. (1963). Organisational Choice: Capabilities of Groups at the Coal Face under Changing Technologies. Tavistock, London.

Turner, A. N. and Lawrence, P. R. (1965). Industrial Jobs and the Worker. Harvard University Graduate School of Business Administration, Boston, Mass.

van Zelst, R. H. (1951). Worker popularity and job satisfaction. Personnel Psychology, 4, 405-412.

Vernon, H. M., Wyatt, S., and Ogden, A. D. (1924). On the Extent and Effects of Variety in Repetitive Work. Medical Research Council. Industrial Fatigue Research Board No. 26. HMSO, London.

Vroom, V. H. (1964). Work and Motivation. Wiley, New York.

and Maier, N. R. F. (1961). Industrial social psychology. Annual Review of Psychology, 12, 413-446.
Walker, C. R. (1950). Steeltown. Harper and Row, New York.

and Guest, R. H. (1952). The Man on the Assembly Line. Harvard University Press, Cambridge, Mass.

Warr, P. B. (1973). Better working lives-a university psychologist's view. Occupational Psychology. 47, 15-22.

Whitsett, D. A. and Winslow, E. K. (1967). An analysis of studies critical of the motivator-hygiene theory. Personnel Psychology, 20, 391-415.

Wilson, N. A. B. (1973). On the Quality of Working Life. Department of Employment, Manpower Papers No. 7, HMSO, London.

Wyatt, S., Fraser, J. A., and Stock, F. G. L. (1929). The Comparative Effects of Variety and Uniformity in Work. Medical Research Council. Industrial Fatigue Research Board No. 52. HMSO, London.

- Langdon, J. N., and Stock, F. G. L. (1937). Fatigue and Boredom in Repetitive Work. Medical Research Council: Industrial Health Research Board No. 77. HMSO, London.

Zaleznik, A., Christensen, C. R., and Roethlisberger, F. (1958). Motivation Productivity and Satisfaction of Workers. Harvard University Graduate School of Business Administration, Boston, Mass.

Received for publication 3 September 1974.

Accepted for publication 26 September 1974. 